\title{
SOCIAL TRUST AND FEELING OF SECURITY IN ETHNIC MACEDONIANS AND ETHNIC ALBANIANS IN THE REPUBLIC OF MACEDONIA
}

\author{
Nikolina Kenig, PhD \\ Ss. Cyril and Methodius University - Skopje, \\ Faculty of Philosophy - Institute of Psychology, \\ E-mail:nikolina@ukim.edu.mk \\ Violeta Petroska-Beshka, PhD \\ Ss. Cyril and Methodius University - Skopje, \\ Faculty of Philosophy - Institute of Psychology \\ Sheruze Osmani Ballazhi, \\ State University of Tetova, Faculty of Philosophy
}

\section{Abstract}

In societies where different ethnic communities experience protracted ethnic or religious tension, high levels of social mistrust and feeling of insecurity are serious psychological barriers to promoting interethnic integration. The purpose of this research is to provide insight into the complex relationships between two empirically extracted dimensions of social trust (perceived collective respect for diversity and perceived collective willingness for cooperation) and personal feeling of security on one hand, with the ethnic background and minority/majority status on a local level on the other.

The convenient sample used in this study consists of 764 participants, $48,3 \%$ ethnic Macedonians and 51,7\% ethnic Albanians (52,2\% females), from 19 towns in the country that differ in the minority/majority status of the two ethnic communities, depending on their ethnic composition. The respondents voluntarily and anonymously 
provided information on their perceptions of the two dimensions of social trust by answering on a six-item subscale from De Rivera's Emotional climate scale (2007) and their personal feeling of security in the country by assessing it on a 7-point Likert scale.

It was hypothesized that both independent factors (ethnicity and minority/majority status) will produce differences along all measured variables. The two-way ANOVA results showed that the two ethnic communities differ in respect to both dimensions of social trust and the personal feeling of security. In addition, there is a difference in the feeling of security that stems from minority/majority status on a local level, whereas this variable interacts with the ethnic background only in regard to the perceived collective willingness for cooperation. The results were interpreted within the frame of the existing inter-ethnic relations in the country and discussed from the perspective of their consequences in improving the overall emotional climate in the society.

Key words: social trust, feeling of security ethnicity

\section{Introduction}

Recent scholarly research and discussions have become attentive in assessing the effects of ethnic diversity on social trust and social participation. Particularly interesting questions are whether the ethnic diversification leads to erosion of trust and increase in the overall feeling of social cohesion and security.

The existing historical, social, religious, and language differences between the two major ethnic communities in the Republic of Macedonia - Albanians and Macedonians - have contributed to parallel coexistence and lack of interaction. The violent conflict between these two communities that started more than fifteen years ago ended with the Ohrid Framework Agreement that introduced measures to improve the status of the ethnic Albanian community. This agreement is still predominantly perceived as inefficient in resolving the issues of mutual mistrust and relatively high interethnic distance (Pecijarevski, 2011) despite the relative cooperation at governmental and institutional levels (eg. Rosulek, 2011). The lack of social cohesion is the underlying cause for instability in inter-ethnic relations. One of the few empirical analysis carried out in the country, suggests that the social capital of Macedonian 


\section{Security}

society is very weak, leading to poor social cohesion and political stability and distrustful and distant inter-ethnic relations (Maleska, 2010).

The role of social trust and a perceived personal security in providing social cohesion

In explaining the concept called culture of peace, de Rivera points out that it can be defined as a multifaceted variable encompassing several wide measurable areas such as social norms, gender equality, democratic participation, open communication, respect for human rights, sustainable development and social cohesion and tolerance (de Rivera, 2007, 2009a; de Rivera \& Paez, 2007). When the society applies appropriate mechanisms to address and obtain promotion of these eight core dimensions, these measures effectuate in relevant behavior of the majority of people. In such countries, people report having less fear of speaking, less anger at the government and less insecurity, and experience more social trust and care for the others out of the immediate family (de Rivera, 2009b). Further, it is also expected that they would be more able to accept differences without emotionally negative responding to them and respect each person's uniqueness and identity. It is proposed that under such overall psychological conditions, it is more likely that communities will take into account the plurality of people's values and interests and support resolution of conflicts without violence (Bar-Tal, Halperin \& de Rivera, 2007).

In de Rivera's view, the objective measures for any of these areas can be related to subjective self-reported measures of a nation's emotional climate (de Rivera, 1992).Therefore, the aspect of overall culture of peace labeled as social trust and tolerance could be operationalized as the extent to which understanding, tolerance, solidarity, and mutual obligation form the basis of the society and its role as a societal feature is of crucial importance in context of crisis or conflict ${ }^{188}$. Simmel (1950, p. 326) describes it as "one of the most important synthetic forces within society" while Fukuyama (1995) defines trust as the expectation that arises in a community on behalf of its members on the basis of shared norms and a belief that the others will behave in mutually supportive ways. Defining social trust in this way actually means accepting the two seemingly opposed approaches in conceptualizing it - the one that understands it as a quality of society rather than of individuals and vice versa. At the individual level, social trust is associated with pro-social behavior (Sønderskov, 2011), while at the state 
level, those societies where high-trusting people dominate are also those with better democratic governance and higher tolerance for diversity (Knack, 2002). Although not much research has been done to support the idea of mutuality of the individual and societal level of social trust, there is some evidence showing that countries with high trust scores have more trustworthy and honest citizens (Knack and Keefer 1997; Basabe \& Valencia, 2007). Building on this notion, social trust could be meaningfully measured by using attitudinal survey questions although the approach that would include behavioral measures as well would be more valid (Glaeser, Laibson, Scheinkman \& Soutter, 2000).

Collective emotions that shape individual and societal reactions in crisis and conflict are always accompanied with an overall feeling of security which might refer to personal and collective security separately (Bar-Tal, Jacobson, \& Freund, 1995). This feeling of security is considered to be based mainly on cognitive assessments, although the affective component is always present as well. It is defined as a general evaluation of the ration between perceived threat or danger versus available defenses and the ability to cope with the perceived threat or danger (Bar-Tal, Halperin \& deRivera, 2007). In addition to demonstrating the meaningfulness of measuring the experience of security, research has shown that the national emotional climate accounts more to feelings of being secure or insecure than the socioeconomic status does (Mahoney \& Pinedo, 2007). Thus, this concept can at the same time be treated as part of the emotional climate and as its consequence.

Taking into account the important role of the discussed concepts in developing a context for non-violent resolution of conflict and their not yet well examined role in forming political attitudes in multiethnic societies with protracted interethnic conflicts (Canetti-Nisim, Ariely \& Halperin, 2008), as well as the need to obtain data on these relevant constructs from the region (Fritzhand \& Petricevic, 2014), we have conducted this study in order to enrich the body of research with data on the extent of social trust and perceived personal security of the two largest ethnic groups in the Republic of Macedonia as well as to examine the relationships between the group status (minority or majority) on a national level and local level on one hand and the perceived trust and security on the other. 


\section{Securuility}

\section{Relevant research}

It has been demonstrated that the higher the level of ethnic diversity within a community, the lower the level of trust (Rice and Steele, 2001). Research suggests that ethnicity can be related negatively to social trust only in communities that belong to ethnic minorities (e.g. Alesina \& La Ferrara, 2002; Post, 2011; Smith, 1997). The reason that social trust is lower among ethnic minorities is ascribed to their frequent experiences with negative stereotyping, discrimination and lower socio-economic status (Smith, 2010).

In answering the question about whether ethnic diversity has negative effect on trust, Dinesen \& Sønderskov (2015) empirically demonstrate that ethnic diversity in the micro-context affects social trust negatively, but that the effect vanishes in a larger context. The authors propose that their findings suggest that interethnic exposure (not contact) underlies the negative relationship between social trust and ethnic diversity (in residential contexts $)^{189}$. It might be expected that heterogeneity produces even less social trust in contexts where different ethnic groups have history of conflicts and tensions and where multiculturalism is not fostered systematically through education (Bahry, Mikhail, Kozyreva, \& Wilson, 2005; Håkansson \& Sjöholm, 2007).

Recent studies mostly suggest that ethnic diversity challenges cooperation. In a European context, a negative link between ethnic diversity and cooperation has been confirmed both at attitudinal and behavioral measures of cooperation. Further, it has been confirmed that the willingness for cooperation varies in accordance to several relevant variables such as the diversity composition of the region, the composition of social networks and the quality of the inter-ethnic contacts (Sturgis, Brunton-Smith, Kuha \& Jackson, 2014; Ulsaner, 2012; Veit, 2015). The decline of social cohesion and cooperativeness in multi-ethnic societies is explained in several ways and one of the most plausible seems to be that it is mediated by the anxieties of the unknown (e.g. Islam \& Hewstone, 1993). On the other hand, in a meta-analysis of several existing studies, Schaeffer (2014) claims that the debate of the associations between ethnic diversity and social cooperation is yet rather inconclusive.

\footnotetext{
${ }^{189}$ These results relate to the multiethnic composition of immigrant residence areas in Denmark and most closely resemble the conclusions from a study conducted in New Zealand (Sibley et al. 2013).
} 
In line with these findings, it was hypothesized that ethnic Albanians (minority) have lower social trust and personal feeling of security than ethnic Macedonians (majority). In addition to the effect of the status of minority vs. majority at the national level, we will examine the effect of this status on a local level, with the expectation that it also reflects on the social trust and personal feeling of security in the same direction. However, our expectation is that the two status levels have different effects on the examined dimensions of social trust. As per perceived willingness for cooperation $\left(\mathrm{H}_{1}\right)$, it was hypothesized that the main effect of minority/majority status will appear only at the national level (with ethnic majority scoring lower). The reason of proposing that being majority on a national level is associated with decrease in perceived willingness for cooperation is the well documented 'fear of otherness' which is more typical for groups that are majorities. On a local level, the status will not produce significant difference, but following the same line of reasoning, the lowest average is expected in ethnic Macedonians who live in cities where they are majority.

In regards to respect for diversity $\left(\mathrm{H}_{2}\right)$, it was expected that the first main effects will be significant (status on a national level) and that ethnic Albanians who are minority on a local level demonstrate the lowest scores because the outcome will be fortified due to the "double" minority status. A similar reasoning applies for perceived personal security $\left(\mathrm{H}_{3}\right)$ It is expected that both main effects will make difference in lowering the means of minorities and in addition, that ethnic Macedonians will have lowest feeling of being secure (interactive effect).

\section{Method}

\section{Participants}

The convenient sample used in this study consists of 764 participants, $48.3 \%$ ethnic Macedonians and $51.7 \%$ ethnic Albanians (52.2\% females) from 19 towns in the country that differ in the minority/majority status of the two ethnic communities, depending on their ethnic composition ${ }^{190}$. Their minimal education level was 12 years of schooling and the age range was $18-58(M=34 ; S D=10.3)$.

\footnotetext{
${ }^{190}$ For instance, according to the proportion of inhabitants, Skopje is a place of living where ethnic Macedonians are majority, whereas in Debar they are minority.
} 


\section{Seccurity}

They participated voluntarily in the study and were recruited on the basis of fitting into the following required criteria: ethnic background, age group, place of living and gender. They were answering the questions anonymously in a presence of previously trained questioners.

\section{Measurements}

De Rivera (2007) constructed a 24-item scale aimed to measure the collective feelings related to security, insecurity, confidence, depression, anger, love, fear, and trust. The construct has 5 facets organized in respective subscales. In this research, only the social trust subscale has been taken into account. This questionnaire consists of 6 items that are responded on a 7-point Likert type scale. For this particular group of respondents it has a reasonable internal consistency of Cronbach alpha $r=0.60$. Further analysis of the items performed by factor analysis (principal components with Varimax rotation) has shown that five of them fit into a two-factor model that explains $52 \%$ of the variance. In this study these two factors were treated as separate dimensions of social trust: perceived collective respect for diversity (3 items) and perceived collective willingness for cooperation $\left(2\right.$ items $\left.{ }^{191}\right)$. For simplicity, in the further text they will be referred to as "respect for diversity" and "willingness for cooperation".

In order to measure the personal feeling of security, the study employed a simple approach of asking participants how secure they feel in the country and having them assess it on a seven-point scale ranging from 1=not at all to $7=$ fully, with 4 being a neutral position (neither secure not insecure). All included questions were translated by the forward-backward method from Macedonian in Albanian by two bilingual persons. Thus, each participant could respond in their mother language.

\section{Results}

Variables included in the study are described in terms of mean averages, standard deviations and their correlations with gender and age (Table 1). Table 2 contains information on the mean averages and standard deviations for each of the relevant subgroups that are included in the further analysis. The averages for the two

\footnotetext{
191 Taking into account that one item has equal loadings on the two factors, it has been removed from the further analysis.
} 
dimensions of social trust are around or below the neutral point. In other words, on average, participants feel neither safe nor unsafe $(M=3.76)$, and perceive that there is a little respect for diversity $(M=10.15 / 3=3.38)$ and willingness for cooperation $(M=5.88 / 2=2.94)$. These three variables, as it could be expected, correlate significantly. Whereas gender does not appear to be associated with any of the examined variables, age is positively connected to willingness for cooperation $(r=0.11 ; p<0.01)$ and security $(r=0.36 ; p<0.01)$.

Table1. Descriptive statistics and Pearson correlations for the variables

\begin{tabular}{llllllllll}
\hline & $\mathrm{M}$ & $\mathrm{SD}$ & $\mathrm{X}_{\min }$ & $\mathrm{X}_{\max }$ & 1 & 2 & 3 & 4 & 5 \\
\hline $\begin{array}{l}\text { 1. Collective respect for } \\
\text { diversity }\end{array}$ & 10.15 & 3.36 & 3 & 21 & - &. & & & \\
$\begin{array}{l}\text { 2. Collective willingness } \\
\text { for cooperation }\end{array}$ & 5.88 & 2.15 & 2 & 14 & $.88^{* *}$ & - & & & \\
$\begin{array}{l}\text { 3. Personal feeling of } \\
\text { security }\end{array}$ & 3.76 & 1.96 & 1 & 7 & $.44^{* *}$ & $.13^{* *}$ & - & & \\
$\begin{array}{l}\text { 4. Gender } \\
\text { (1=male;2=female) }\end{array}$ & 1.52 & 0.50 & - & - & -.03 & -.40 & .03 & - & \\
5. Age & 34.1 & 10.20 & 18 & 58 & .03 & $.11^{* *}$ & $.36^{* *}$ &, 02 & - \\
\hline $.01{ }^{*} \mathrm{p}<.05$ & & & & & & & & &
\end{tabular}


Table2. Descriptive statistics for the included variables for the subgroups

\begin{tabular}{|c|c|c|c|c|c|c|c|c|c|}
\hline \multicolumn{4}{|c|}{ Local level Majority } & \multicolumn{2}{|c|}{ Minority } & \multicolumn{3}{|c|}{ Total } & \multirow[b]{2}{*}{ SD } \\
\hline $\begin{array}{r}\text { Collective respect for } \\
\text { diversity }\end{array}$ & $\mathbf{N}$ & $M$ & SD & $N$ & $M$ & SD & $N$ & M & \\
\hline Ethnic Macedonians & 341 & 11.02 & 3.40 & 28 & 10.85 & 3.63 & 369 & 11.00 & 3.42 \\
\hline Ethnic Albanians & 230 & 9.58 & 3.29 & 160 & 8.98 & 3.56 & 3.41 & 9.33 & 390 \\
\hline Total & 571 & 10.43 & 3.43 & 188 & 9.25 & 3.62 & 3.51 & 10.10 & 759 \\
\hline Local level & \multicolumn{3}{|c|}{ Majority } & \multicolumn{3}{|c|}{ Minority } & \multicolumn{2}{|c|}{ Total } & \\
\hline $\begin{array}{l}\text { Collective willingness } \\
\text { for cooperation }\end{array}$ & $\mathbf{N}$ & M & SD & N & M & SD & N & M & SD \\
\hline Ethnic Macedonians & 341 & 5.61 & 2.44 & 28 & 5.43 & 2.21 & 369 & 5.59 & 2.33 \\
\hline Ethnic Albanians & 231 & 6.17 & 2.31 & 163 & 6.34 & 2.55 & 394 & 6.23 & 2.48 \\
\hline Total & 572 & 5.83 & 2.35 & 191 & 6.20 & 2.61 & 763 & 5.92 & 2.43 \\
\hline Local level & \multicolumn{3}{|c|}{ Majority } & \multicolumn{3}{|c|}{ Minority } & \multicolumn{2}{|l|}{ Total } & \\
\hline $\begin{array}{r}\text { Personal feeling of } \\
\text { security }\end{array}$ & $\mathbf{N}$ & M & SD & $\mathrm{N}$ & M & SD & $\mathrm{N}$ & M & SD \\
\hline Ethnic Macedonians & 341 & 4.53 & 1.87 & 28 & 3.89 & 2.80 & 369 & 4.49 & 1.85 \\
\hline Ethnic Albanians & 231 & 3.22 & 1.82 & 164 & 2.91 & 1.70 & 395 & 3.09 & 1.81 \\
\hline Total & 572 & 4.00 & 1.95 & 192 & 3.05 & 1.79 & 764 & 3.76 & 1.96 \\
\hline
\end{tabular}

For testing the hypotheses, two-way ANOVA was performed ${ }^{192}$, with minority/majority on national level, i.e. ethnicity (MIN/MAJ-NAT) and minority/majority on local level (MIN/MAJ-LOC) treated as independent variables. The results are presented in Tables 3-5.

${ }^{192}$ All performed Levine tests for homogeneity of variances allowed the further comparisons. 


\section{Securuliauses}

Table 3. Analysis of variance for Willingness for cooperation

\begin{tabular}{lrrrrr}
\hline Source & $\begin{array}{c}\text { Type III Sum of } \\
\text { Squares }\end{array}$ & df & Mean Square & \multicolumn{1}{c}{ F } & \multicolumn{1}{c}{$\mathbf{p}$} \\
\hline Corrected Model & 81.56 & 3 & 27.18 & 4.66 & .003 \\
Intercept & 11290.70 & 1 & 11290.70 & 1936.81 & .000 \\
MIN/MAJ-NAT & 43.68 & 1 & 43.68 & 7.49 & .006 \\
MIN/MAJ-LOC & .005 & 1 & .005 & .00 & .977 \\
LOC * NAT & 2.56 & 1 & 2.53 & .43 & .510 \\
Error & 4424.61 & 759 & 5.83 & & \\
Total & 31330.000 & 763 & & & \\
\hline
\end{tabular}

The hypothesis that the status of minority on national level is associated with lower perceived willingness for cooperation is supported by the findings. The significant main effect $\left(F_{\text {nat }}(1)=7.49 ; p<.01\right)$ of ethnicity means that the minority status on a national level is accompanied with higher social trust that stems from perceived willingness for cooperation on a societal level, which is confirmatory finding for the first part of the proposed hypothesis. The expected absence of significant differences on a local level is also confirmed. The post-hos test conducted to examine whether ethnic Macedonians who live in cities where they are minority have lowest average on this variable, did not fully support the expectation. The only significant difference $(p<0.05)$ has been found between them and the ethnic Albanians who are minority at both levels. Thus, $H_{1}$ is mostly, but not fully confirmed.

Table 4. Analysis of variance for Diversity respect

\begin{tabular}{lrrrrr}
\hline Source & $\begin{array}{c}\text { Type III Sum of } \\
\text { Squares }\end{array}$ & df & Mean Square & \multicolumn{1}{c}{ F } & \multicolumn{1}{c}{ p } \\
\hline Corrected Model & 566.74 & 3 & 188.92 & 16.18 & .000 \\
Intercept & 33189.85 & 1 & 33189.85 & 2843.24 & .000 \\
MIN/MAJ-NAT & 224.03 & 1 & 224.03 & 19.19 & .000 \\
MIN/MAJ-LOC & 11.84 & 1 & 11.84 & 1.02 & .314 \\
LOC * NAT & 3.98 & 1 & 3.98 & 0.34 & .559 \\
Error & 8813.31 & 755 & 11.67 & & \\
Total & 87496.00 & 759 & & & \\
\hline
\end{tabular}




\section{Securiagues rity}

The hypothesis $\mathrm{H}_{2}$ that the status of minority on both national and local level is associated with lower social trust from perspective of perceived respect for diversity on a societal level was only partially accepted. Results presented in Table 4 show that there is a significant difference $\left(F_{\text {nat }}(1)=19.19 ; p<.01\right)$ only between ethnic Albanians and Macedonians (main effectl) and that the status on a local level does not contribute to the dependent variable $\left(F_{l o c}(1)=1.02 ; p>05\right)$. Considering that ethnic Albanians perceive less respect for diversity than ethnic Macedonians, but minorities do not differ from majorities in general (absence of main effect 2), $\mathrm{H}_{2}$ is partially confirmed.

Table 5. Analysis of variance for Perception of security

\begin{tabular}{lrrrrr}
\hline Source & $\begin{array}{c}\text { Type III Sum of } \\
\text { Squares }\end{array}$ & df & Mean Square & \multicolumn{1}{c}{ F } & p \\
\hline Corrected Model & 392.87 & 3 & 130.96 & 39.31 & .000 \\
Intercept & 4312.36 & 1.00 & 4312.36 & 1294.50 & .000 \\
MIN/MAJ-NAT & 108.35 & 1.00 & 108.35 & 32.53 & .000 \\
MIN/MAJ-LOC & 18.18 & 1.00 & 18.18 & 5.46 & .020 \\
LOC * NAT & 2.32 & 1.00 & 2.32 & 0.70 & .404 \\
Error & 2531.78 & 760.00 & 3.33 & & \\
Total & 392.87 & 3.00 & 130.96 & 39.31 & \\
\hline
\end{tabular}

The analysis has shown that both main effects are significant $\left(F_{n a t}(1)=32.53\right.$; $\left.p<.01 ; F_{\text {loc }}(1)=5.46 ; p<.05\right)$ and they are not accompanied with an interactive effect. Being minority both at national and local level is associated with feelings of being less secure, but there is no effect of interaction as it has been hypothesized. Thus, $\mathrm{H}_{3}$ is partially confirmed as well.

\section{Disussion}

Taking into account that all tested hypotheses were partially confirmed, it is very hard to make general conclusions, especially because the issue of social trust is largely underexplored in this particular region. The only indication that appears to be quite clear is connected with the absence of significant interaction effects across all tested variables More precisely, it seems that the impact of being minority or majority 


\section{Seccurity}

generally is the strongest one and that the experiences on a local level do not contribute much towards the cohesion, especially not in a way that it changes the direction of the effect. These finding are not in full congruence with the other studies where it is claimed that mere exposure to others decreases social trust (Aizlewood, \& Pendakur, 2005; Dinesen \& Sønderskov, 2015; Schaeffer, 2014; Veit, 2015). However, it has to be stressed that the comparison cannot be made without special caution regarding the context. Vast majority of studies were conducted in countries or regions where ethnic minorities are immigrants with no significant involvement in the political realm of the state.

Generally, results suggest that being majority on national level is linked to perceiving that the society respects diversity less and to feeling less secure. In most studies these links are explained with experienced or anticipated discrimination, as well as to lower socio-economic status and lower education which often overlaps with the ethnic categorization (Achbari, 2016). This might be a case in the Republic of Macedonia, but that does not mean that there are no alternative explanations. Another plausible interpretation might be that the group identity of minority collectives is built upon the narrative of being less powerful and under threat of oppression (Merino \& Tileaga, 2010; van Dijk, 1993).

Last but not least, it should be stressed that this study has serious limitations that should not be ignored. Firstly, although planned in a way that resembles quota sampling, the sample is convenient. Along with that, very important factors that proved to be salient (Sturgis, Brunton-Smith, Kuha \& Jackson, 2014) were not controlled: the extent of possibilities for contact that provides cooperation and whether some interethic social networks were established or not ${ }^{193}$. In addition, the instruments that were used are very limited in the number of items and the measurements are very robust and even not easily comparable with other similar studies. Another important methodological reminder is that the results are sensitive to the way in which social trust is operationalized and measured ${ }^{194}$.

193 Therefore, although our findings are in line with the conflict theory (Blalock 1967) which claims that social environments induce a feeling of threat in minority and majority groups, that does not necessarily means that they oppose the competing contact theory.

${ }^{194}$ In this particular case, ethnic Macedonians and ethnic Albanians demonstrate differences in opposite directions when the variable is decomposed into two dimensions. Having been measured otherwise, these differences might have been blurred. In this context, it made sense 


\section{Seccurity}

There are several general approaches proposed in relevant literature on how to increase the level of trust in social relationships and the feeling of security. Bar-Tall (2009) proposes reconciliation among groups which have experienced tensions, mistrust and conflict that might begin by institutionalizing values, beliefs, attitudes and practices of culture of peace mainly through education. Another way of building trust in inter-ethnic context is by investing into providing personal contact among individuals from different ethnic backgrounds based on the need for mutual cooperation (Lemmer \&Wagner, 2015) as well as by addressing all kinds of structural inequalities (Portes \& Vickstrom, 2011). This analysis however, once again points to the need of in-depth research of ethnic diversity and its effects on social cohesion that takes a more into account the nuances of the context as well as the perspectives of different groups. Having this in mind, it should be considered as an initiation of further relevant research (preferably both qualitative and quantitative) and debate on this important issue in the region rather than as a conclusive study.

\section{References}

1. Achbari, W. (2016) The Paradox of Diversity: Why does Interethnic Contact in Voluntary organizations does not lead to generalized trust? Brussels: Springer International Publishing.

2. Aizlewood, A., and R. Pendakur. (2005). "Ethnicity and Social Capital in Canada". Canadian Ethnic Studies 37, 2, 77-102.

3. Alesina, A., \& La Ferrara, E. (2002)." Who trusts others?" Journal of Public Economics, 85, 207-234.

4. Bahry, D., Mikhail, K., Kozyreva, P. \& Wilson, R.K. (2005). "Ethnicity and Trust: Evidence from Russia“. American Political Science Review, 99, 4, 521-532.

5. Bar-Tal, D., Halperin, E. and de Rivera, J. (2007). "Collective Emotions in Conflict Situations: Societal Implications". Journal of Social Issues, 63, 2, 441460.

to perform the division of the variable, because we took into account the history and the reality of the relations between these two communities and the current developments as well. In the period when this research has been carried out (December 2016), the messages conveyed as part of the campaign for the parliamentary elections might have left their impact on the overall answers. 


\section{Securiagues}

6. Bar-Tal, D., Jacobson, D., \& Freund, T. (1995) )"Security feelings among Jewish settlers in the occupied territories: A study of communal and personal antecedents". Journal of Conflict Resolution, 39, 353-377.

7. Bar-Tal, D. (2009) Reconciliation as a Foundation of Culture of Peac. lin: J. De Rivera, (Ed.) Handbook on Building Cultures of Peace, New York: Springer. pp. 363-377.

8. Basabe, N. \& Valencia, J. (2007) "Culture of Peace: Sociostructural Dimensions, Cultural Values, and Emotional Climate", Journal of Social issues, 63, 2, pp. 405-419.

9. Canetti-Nisim, D., Ariely, G. \& Halperin, E. (2008) "Life, Pocketbook, or Culture: The Role of Perceived Security Threats in Promoting Exclusionist Political Attitudes towards Minorities in Israel". Political Research Quarterly, 61,1, pp. 90-103.

10. De Rivera, J. \& P'aez, D. (2007) “Emotional Climate, Human Security, and Cultures of Peace". Journal of Social Issues, 63, 2, pp. 233-253.

11. De Rivera, J. (1992) Emotional climate: Social structure and emotional dynamics. In K. T. Strongman (Ed.), International review of studies on emotion (Vol. 2,). New York: John Wiley, pp. 199-218.

12. De Rivera, J. (2007) "Transforming the empire with a department of peace". Peace and Change, 32, pp. 4-19.

13. De Rivera, J. (2009a) "Building Cultures Of Peace That Protect Human Rights". Psyke \& Logos, 30, pp. 14-27.

14. De Rivera, J. (2009b) Assessing the peacefulness of cultures. In J. de Rivera (Ed.) Handbook on building cultures of peace, New York: Springer pp. 89-103

15. Dinesen, P.T. \& Sønderskov, K.M. (2015) "Ethnic diversity and Social Trust: Evidence from the Micro-Context American", Sociological Review, 80, 3, pp. 550-573.

16. Fukuyama, F. (1995) Trust: The social virtues and the creation of prosperity. New York: Free Press

17. Fritzhand, a. \& Petricevic, N. (2014) "The Culture of Peace: Student's Perception of the Emotional Climate in the Republic of Macedonia". Social Dialogues, 5/1, pp. 145-162.

18. Glaeser, E., Laibson, D., Scheinkman, J., \& Soutter, C. (2000) "Measuring trust". The Quarterly Journal of Economics, 115, pp. 811-846. 


\section{Securiagues rity}

19. Håkansson, P. \& Sjöholm, F. (2007) "Who Do You Trust? Ethnicity and Trust in Bosnia and Herzegovina". Europe-Asia Studies, 59, pp.961-976.

20. Islam, R. M., \& Hewstone, M. (1993) "Dimensions of contact as predictors of intergroup anxiety, perceived out-group variability, and out-group attitude: An integrative model". Personality and Social Psychology Bulletin, 19, pp.700-710.

21. Knack, S. (2002) "Social Capital and the Quality of Government: Evidence from the States". American Journal of Political Science, 46, 4, 772-85.

22. Knack, S., Keefer, P. (1997) "Does Social Capital Have an Economic Payoff? A Cross-Country Investigation". Quarterly Journal of Economics 112, 4, pp. 12511288.

23. Lemmer, G \& Wagner, U. (2015) "Can we really reduce ethnic prejudice outside the lab? A meta-analysis of direct and indirect contact interventions". European Journal of Social Psychology 45, 2, pp.152-168.

24. Mahoney, C.0. \& Pinedo, T. M. (2007) "Human Security in Communities in Costa Rica and the United States". Journal of Social Issues, 63, 2, pp. 353-368.

25. Maleska, M. (2010) Interethnic relations in Macedonia: People Centred Analyses, New Balkan Politics, 12, http://www.newbalkanpolitics.org.mk/item/INTER-ETHNIC-RELATIONS-INMACEDONIA:-PEOPLE-CENTRED-ANALYSES\#.WHzcDH3UbOk, (visited on January $\left.16^{\text {th }}, 2017\right)$

26. Merino, M. \& Tileaga, C. (2011) "The construction of ethnic minority identity: A discursive psychological approach to ethnic self-definition in action", Discourse and Society, 22/ 1, 86-101. DOI: 10.1177/0957926510382834

27. Pecijarevski, M. (2011) "The Role of inter-ethnic conflicts on the integration of the Macedonian society" In Daskalovski, Z \& Risteska, M (eds.) One Decade after the Ohrid Framework Agreement: Lessons (to be) Learned from the Macedonian Experience, Skopje: Center for Research and Policy Making, pp. 138-169.

28. Portes, A. \& and Erik Vickstrom, E. (2011) "Diversity, Social Capital, and Cohesion". Annual Review of Sociology, pp. 37, pp. 461-499. 
29. Post, D. (2011) Social Trust among Ethnic Minorities: How trustful are Germany's immigrated ethnic minorities? Unpublished Master thesis Research Master Social Cultural Science Radboud University Nijmegen,www.ru.nl/publish/pages/757346/m_scthesis_danipost_20_10_2011. pdf, (visited on January $9^{\text {th }}, 2017$ )

30. Putnam, R. (2000) Bowling Alone: The Collapse and Revival of American Community. New York: Simon and Schuster.

31. Rice, T. W. \& Steele, B. (2001) "White Ethnic Diversity and Community Attachment in Small lowa Towns". Social Science Quarterly. 82, pp. 397-407.

32. Rouslek, P. (2011) "Macedonia in 2011 - on the way towards stabilization or before the new 'grand' agreement?" In Daskalovski, Z \& Risteska, M (eds.) One Decade after the Ohrid Framework Agreement: Lessons (to be) Learned from the Macedonian Experience, Skopje: Center for Research and Policy Making, pp.66-85.

33. Schaeffer, M. (2014) Ethnic Diversity and Social Cohesion. Immigration, Ethnic Fractionalization and Potentials for Civic Action. Dorchester: Henry Ling Limited

34. Sibley, C. G., John D., Robin B., Danny 0., Ryan P. Frank A., Andrew R., Gavin A., Wilson, M.S. \& Barlow, F.K. (2013) A Dual Process Model of Attitudes towards Immigration: Person $x$ Residential Area Effects in a National Sample. Political Psychology 34,4, pp. 553-72.

35. Simmel, G. (1950). The Sociology of Georg Simmel, Glencoe, IIl.: Free Press.

36. Smith, S. S. (2010). "Race and Trust". Annual Review of Sociology, 36, pp. 453475.

37. Smith, T. W. (1997). "Factors Relating to Misanthropy in Contemporary American society". Social Science Research, 26, pp. 170-196.

38. Sønderskov, K. M. (2011). "Explaining Large-N Cooperation: Generalized Social Trust and the Social Exchange Heuristic". Rationality and Society, 23, 1, pp. 5174.

39. Sturgis, P. Brunton-Smith, I., Kuha, J. \& Jackson, J. (2014). "Ethnic diversity, segregation and the social cohesion of neighborhoods in London", Ethnic and Racial Studies, 37, 8, 1286-1309 D0I: 10.1080/01419870.2013.831932

40. Uslaner, E. (2012). Segregation and Mistrust: Diversity, Isolation, and Social Cohesion. Cambridge: Cambridge University Press. 
41. Van Dijk, T.A. (1993). Analyzing racism through discourse analysis. In J.H. Stanfield II \& F. M. Dennis (Eds.) Race and ethnicity in research methods. Newbury Park, CA: Sage, pp.92-134.

42. Veit, S. (2015). Ethnic diversity and cooperation: Causality, Linking Mechanism, and Contexts. Dissertation: Freie Universität Berlin, https://www.wzb.eu/en/research/migration-and-diversity/migrationintegration-transnationalization/projects/ethnic-diversity-trust-an, (visited on January $\left.14^{\text {th }}, 2017\right)$.

43. Welch, M.R., Rivera, R.N., Conway, B.P., Yonkoski, J., Lupton, P.M. \& Giancola, R. (2005). Determinants and Consequences of Social Trust. Sociological Inquiry, 75, 4, pp. 453-473. 